\title{
Breasts, Bodies, Art: Central Desert Women's Paintings and the Politics of the Aesthetic Encounter
}

\section{Jennifer L. Biddle}

This essay is concerned with a culturally distinctive relationship between breasts and contemporary art from Central Desert Aboriginal women, specifically, recent works by Emily Kame Kngwarreye, Kathleen Petyarre and Dorothy Napangardi. ${ }^{1}$ Contra to the dominant interpretation of these paintings as representations of 'country' - cartographic 'maps' of the landscape, narratives of Dreaming Ancestors, flora, fauna, species - my argument is that these works bespeak a particular breasted experience and expression, a cultural way of doing and being in the world; what I want to call a breasted ontology.

This breasted ontology is literally manifest in the ways in which these paintings are produced and, in turn, experienced by the viewer. That is, these works arguably engender a bodily relation between viewer and image. This viewing relation is not a matter of a viewing subject who, kept at a distance, comprehends an object of ocular focus and vision. Rather, this relation instead is one in which the viewer relinquishes her sense of separateness from the canvas; where a certain coming-into-being in relation to the painting occurs. One does not so much know these works cognitively as lose oneself in them. Through viewing these works, as it were, one becomes vulnerable to their sensibilities in so far as they incite an enmeshment, an enfolding, and encapturing, even in their materiality. 
These works are profoundly affective: haptic, kinaesthetic, tactile. They are, in Deleuze's sense, 'sensation' in so far as what is painted is lived-experienced as sensation-in the body of the viewer herself. ${ }^{2}$

I am not concerned with what these paintings mean but what they do. And what they do, to put it crudely, is to engender a way of being otherwise at threat. As I have explored elsewhere, these paintings have arisen in a context of ongoing assailing effects of colonialism-dispossession, displacement, land rights, native title. ${ }^{3}$ They can be seen as a certain writing back to what John von Sturmer argues is a historically enshrined institutional incapacity of Europeans to 'recognise' Aboriginal ways of being. ${ }^{4}$ If these works operate to produce ontological affectations, they do so in a climate where there has been a no uncertain failure to hear.

I want to juxtapose here a difference between hearingthat is, a cognitive processing of word, meaning, information - with a more bodily and affective experience, in order to illustrate a shift currently taking place in contemporary Central Desert painting. Over the last decade, a number of related changes have occurred in both formal aspects of these works, and their presentation in art galleries and coffee table books. In terms of form, there is an increasing absence of so-called 'icon'-based figures in these works - a form reliant upon a Dreaming story and/or iconic de-codings - to a form which increasingly has no conceivable 'icons' at all. Further, no longer do Dreaming stories - the dominant contextual presentation of these works as they make their way from desert communities to the galleries of London, Paris, New York - accompany these works. A minimal use of titling, often in English-only, is becoming more common. Finally, there is a movement towards what might be called a greater formal abstraction in these paintings, at least in Western aesthetic terms.

These changes indicate an important shift in emphasis. The emphasis currently appears to be less on what is being signified-place, site, Ancestor - than on signification itself. Or to put that slightly differently, these works are performative in the sense we understand from Judith Butler - they 
bring into being what they purport to represent. ${ }^{5}$ It is their very materiality which needs analysis. In so far as the Dreaming has an ontological status, it needs to be understood actively; how acts of repetition, materially, constitute it. Repetition is constitutive. Perhaps increasingly, in the kind of colonial and postcolonial contexts in which these paintings take shape, a context necessarily of threat, the imperative to perform these acts is even greater.

What are the intercultural political possibilities engendered by this distinctive movement on behalf of women artists? In order to explore the possible implications of these works, I must further explain what I mean by breasted ontology. Put crudely, my argument is that the affectivity of these works is engendered by the materiality of the mark; not what these marks mean but how these marks are made. I identify below five axioms of so-called breasted ontolology.

Axiom one: these works derive from marks made on the breast. That is, the breast is a primary site for Ancestral imprintation.

Contemporary women's art in the Central Desert arises from marks first made on the front of the body - the upper chest, arms and breasts - in a women-only ceremonial ritual Dreaming performance that Warlpiri call Yawulyu and Anmatyerr/Alyawarr call Awelye.

At the most general level, the marks and designs of Yawulyu serve to highlight the size, weight, movement and, specifically, the fall of the breast. And it should be noted preliminarily that these marks are both material and visual, haptic and scopic - that is, they are felt as they are made to be seen (and more felt than seen by the women who adorn them).

What is privileged is the fallen breast, and hence, age is here valued. To be a proper Yawulyu performer is to be postchild-bearing age. The very aspects of the breast that the bra is explicitly designed to constrain and mask and hence, in our cultural terms, the most taboo aspect of the aged breast-its 'fallen', 'saggy' nature - is here exalted. It is the very capacity of the breast to move, to quiver, to tremble and shake, which is valued. ${ }^{6}$

The larger the surface for painting the better. Warlpiri women equate ceremonial leadership prowess and potency 
with large breasted-ness. Size itself is accentuated by the mark. Sometimes the breast appears widened by concentric circles and half-moons; sometimes elongated by vertical lines; all of which end, not incidentally, just at the nipple. The areola for Warlpiri, at least in relation to inscription, is of no consequence. The nipple is never incorporated into the design but rather, serves as its nadir, the point literally which the inscription works to accentuate. And, as I return to below, the nipple is also, of course, the literal site of feeding, of fecundity.

Not only the ochre designs but also the dance of Yawulyu itself is performed precisely to emphasise this weight and fall of the breast. A certain slow speed jump forward is made where the feet don't actually leave the ground and yet manage to slowly, measurably, compel the dancer forward, undulating the breast vertically each time-far more the point it seems than any actual distance covered. The breast rises, falls, slaps, rhythmically against the body with a thwarted start and stop so that the breast moves, vibrates and stills again, a tremulousness produced of both flesh and design.

This rhythmic, repetitive, rocking-like movement arguably mimetically repeats the suck-suck-pause pattern of the infants' feed, marked by lulls and waits and pulse as much as by flow. The breast is compelled downward towards a no-longer static or inert ground-country-that simply provides a platform for the dancing. But this is ground-country-which is enlivened by the pounding of the dancer's feet, the slapping of the breasts in rhythm with the singers' voices and the swirling of the dust engendered, which appears as almost an active partner to the dancers, moving, rising up to meet the breast in 'fall', like the infant, pulling for a feed.

Axiom two: the breast marks as it makes and makes as it marks. It is not only that the breast is itself inscribed but that the breast itself inscribes. Here the breast is figured as a writing instrument which makes marks as felt as they are seen, as material as they are visual.

What we see depicted in these paintings is not a breast of 'natural' fecundity. Rather, this is a breast represented as always already-marked, worked by exacting and precise techniques of ritualised inscription and performance. In this 
sense, the breast represented is neither naked (Walpiri have no term for naked or bare breast) nor is it, strictly speaking, 'human'.

In the early collections of acrylic paintings produced by Warlpiri women at Lajamanu, and Anmatyerr/Alyawarr women at Utopia, breasts are the dominant motif. ${ }^{7}$ What we see in these early works from Utopia, particularly, is the breasts themselves. Breasts in pairs, single or double, always painted up, always, it seems to me, mid-dance, for it is their procreative potency which is here represented. Disembodied from the bodies of the dancer, these painted-up breasts are both foreground and background, at once floating and fixed. The outline of their shape disappears in contrast to the very 'stuff' of the dots, lines and marks they engender. For these are fecund breasts; breasts that drip, seep, weep. These breast mark and make. These are breasts which are productive and reproductive in a far more active way than western notions of 'lactation' suggest.

What makes painted-up breasts generative is that they repeat an initial Ancestral imprintation of country. How marks are put and re-put on breasts, and in turn, on canvas, engenders efficacy in the same material terms initial Ancestral potency was engendered.

Ancestors first roamed an unmade and unmarked landscape as they traversed the country, fighting, defecating, hunting, as people do today, and transforming their so called 'subjective' and profoundly corporeal experiences and expressions, as Nancy Munn first called them - blood, semen, breast milk, bones, piss - into the 'objective' geographical features of the landscape during the time of what Warlpiri call Jukurrpa - the Dreaming. ${ }^{8}$ Even if disengaged from the body of Ancestors, these sites, places, and marks continue to hold precise affiliations and identifications, as well as powerful and potentially dangerous forces. Hence, the constitutive power and effect associated with putting these marks by contemporary Warlpiri-rejuvenating country or species; controlling fertility; causing illness and healing; regulating social relations and relatedness are some of these effects.

Warlpiri call these marks kuruwarri-a complex term meaning Ancestral presence, essence, trace and birthmark 
and/or freckle. Kuruwarri are thus both the marks and traces left in country as it was made and the marks that people now put on ground, skin, canvas - not as representations of country but as country. Arguably, what Dreaming Ancestors themselves discovered as they marked, made, imprinted the landscape, is exactly what is repeated by contemporary painters. What these paintings demonstrate is a procedural enactment of how it is that canvas, country, skin are knowable-mark-able, make-able, as the same stuff.

Kuruwarri also means 'birthmark, freckle'-a much overlooked aspect of the meaning of these marks. The emphasis on country, the concomitant interpretation of acrylic paintings as 'maps of country' has resulted in an understanding of the only possible referent, the over-determined signified, of kuruwarri signs being the literal cartographic country itself. No doubt, this results from the protracted and equally over-determined history of Warlpiri-European relations, that is, the result of ongoing assailing effects of land rights, royalty negotiations, native title. And it is not insignificant that acrylic paintings have been submitted in evidence in land hearings. Warlpiri women regularly performed Yawulyu at early hearings and, effectively, had the way in which the Land Rights Act was interpreted changed, to have maternally linked kin included in notions of primary 'owner', as Hamilton has argued. ${ }^{9}$

What gets overlooked in this context however is that kuruwarri are embodied traces and imprints. Embodied originally by Ancestors - these marks have visceral effects because they are visceral remains. In turn, they provide a necessary material intercorporeal means for linking Ancestral bodies to human bodies in crucial ways. It is not only in country itself that Ancestral visceral presence resides but these presences (located in certain sites and affiliated with certain species) can enter women's wombs, cause conception and, in turn, leave birthmark, freckles and other identifying traits of specific kinds of subjectivity upon individuated Warlpiri. ${ }^{10}$ This is why the term kuruwarri also refers to corporeal imprintation. The fleshly traces of birthmarks and freckles are indicative of how 'skin' is literally, materially, the same 'substance' as country, in that it is equally a medium in which Ancestral traces reside. 
Cicatrices - ritual scarifications - provide a literal exemplification. Historically, these ridges, lines and gullies were made by incising the skin and the incisions were then packed with site-specific country for the permanent housing of country in the flesh.

This left a permanent mark for both sight and touch $-\mathrm{a}$ trace at once reminder and remainder - an affective material impregnation of person with country. According to Christine Watson, Kukatja people liken cicatrices to the ridges made in sand drawing. ${ }^{11}$ The cutting of the head and other forms of scarification in mourning and bereavement ceremonies and, of course, circumcision and sub-incision ceremonies, indicate the degree to which the somatic surface of the body is, like country itself, understood and treated as a text for Ancestral imprintation. Warlpiri (also) call cicatrices kuruwarri.

This fleshly viscerally imprintable texture of country literally likened to skin is recreated each and every time kuruwarri is put, through three constitutive processes:

First, the body and the canvas are covered, coated, in totality. In Yawulyu (women's ceremonial Dreaming ritual) the breasts and upper shoulders are first rubbed, coated with oil, emu fat if it is available or, more likely, cooking oil, baby oil or butter.

Each and every act of inscription proceeds, as it were, from scratch. The activities of Ancestors who initially roamed an unmarked, unmade landscape are here literally recreated by the conditions of contemporary inscription. Jukurrpa - the Dreaming - is not something which happened once and for all in some absolute past but is repeated, recreated, remade continuously, indeed, one could argue that the condition of Jukurrpa-its constitutive repeatable form - is in fact structured by, to borrow Derrida's framework, iterability. ${ }^{12}$

'Ground' itself is similarly treated. Prior to ceremonies, not only are stones and sticks which might hurt feet carefully removed but the site is brushed, raked, smoothed over, bulldozed even, if the event is a large one; gestures that simultaneously erase and renew.

Canvas is treated in the same manner. Despite already offering what 'we' might think of as a 'blank' surface, canvases are first coated in entirety with one or more (in the case of 
Kathleen Petyarre) background 'colour' prior to any other paint application. This 'background' preparation of the canvas makes the productivity of the mark-Ancestral imprintation-possible.

Warlpiri use a particular word for this process: maparni. The Warlpiri Dictionary defines maparni: 'to anoint [with oil (JARA)], paint, grease (with fat/oil), smear, rub on, rub with'. ${ }^{13}$ Through maparni; through anointing, a simultaneous erasure and renewal - a transformation of the profane into the sacred-occurs and thus a site is rendered receptive to the inscription of kuruwarri.

Second, marks are made in, not on, the surface. Warlpiri styluses literally drag the mark behind them, the way a finger or stick is dragged through the dirt and leaves a trace in its wake. In Yawulyu, a stick wrapped repeatedly with thread is used; in acrylic painting, a paintbrush, but more likely the finger will be used to 'put' the kuruwarri. There is a friction between stylus and surface. Something happens between implement and surface.

In other words, the kuruwarri sign is not only understood as an imprintational trace but it is literally produced as one. These are not so much visual or aesthetic signs as they are literal marks. And I think here of Derrida and other scholars' emphasis on the gramme, the graph, the glyph, the appreciation of writing as inscription - an appreciation which allows me to focus on writing as a material phenomenology; not that which refers, defers, to speech, sound or word, but rather as a force itself with effects. ${ }^{14}$

Third, the mark is made to move: to quiver, to shake, shimmer. The sense of kuruwarri as material imprintation is further evinced in how the kuruwarri are themselves inscribed prior to any other marking. Kuruwarri signs are put and re-put. Ochre will be dragged and re-dragged on breast; paint will be applied, thick and dark on canvas once, twice, again. A physical frisson as stylus meets flesh again and again - infant mouth to breast-like, it is above else the productivity of the meeting between the two that matters and is literally manifest, in the making of the mark.

This imprinting of flesh will literally continue in the ensuing 'outlining' of the kuruwarri. The impression is 
almost that kuruwarri are the spaces left over from tracing. For in Yawulyu, the red ochre of the kuruwarri mixes with oiled colour of the skin such that what one 'sees' is not the kuruwarri so much as the white ochre traces. The very shape of the kuruwarri-its apprehension as a figure - is manifest only in, through and by the trace which surrounds it. Literally analogous to the signs of Ancestral presence in the landscape, the trace is the determinative, indeed, the only form through which such manifestations of presence are 'seen'.

What is evinced here, it seems to me, is the 'staging of an appearance-as-disappearance', to borrow a phrase from Roland Barthes. ${ }^{15}$ For what is most crucial - the virtual signs of Ancestral presence-disappear as they appear only in repetition. At a crude level, this seems to me to augment the very way in which country itself is only known in and through the repetitions - the marks, rituals, songs, stories - that Warlpiri tell of it, rendering a landscape, a place as known through such cultural 'tellings'.

But this 'appearance-as-disappearance' manifests in terms more compelling yet. For there is an imperative in this movement, in this vacillating, oscillating, at once appearing and disappearing kuruwarri. This doubling 3 -D effect, this vibrancy, this tremulousness of the text, is perhaps the most remarked-upon characteristic of Central Desert Painting. The seemingly 'alive' nature of the canvases creates, as Barbara Glowczewski has put it, 'a movement which ... invites us to penetrate the texture of the canvas'. ${ }^{16}$ The efficacy of kuruwarri marks depends precisely upon this ebullient potentiality; a simultaneous animating of both breast and country. The simultaneous animation of both mother and infant's body is crucial to successful breastfeeding-dependent as the breastfeeding relation is on this mutual mingling of fluid and flesh, that enlivens both mother and child and drives both to continue this pursuit of need and nourishment, pleasure and desire.

Warlpiri call this vibrancy, this 3-D effect, 'shimmering', according to Francoise Dussart. ${ }^{17}$ It is important to stress this potency is not simply available in these kuruwarri signs (as has been previously interpreted), they must be rendered in precise ways to become efficacious, to become performative, 
in and through the kind of work I've described here. The 'latent law' of Jukurrpa, of the Dreaming, as Michael Jackson has put it, must be 'reanimated' to be effective. ${ }^{18}$ As with the Law of lactation - supply equals demand - so too does country require the labour of human efficacy to ensure its fecundity.

In Yawulyu, the aim is to outline the design until the background becomes saturated, so that the kuruwarri, the Ancestral force, enters the body and 'feeds' the woman. The rhythmic, repetitious marking and re-marking literally press the kuruwarri mark in. Christine Watson describes Kukatja sand drawing as causing physical vibrations to the ground which radiate with Ancestral potency. ${ }^{19}$ Arguably, the penetrative imprinting 'dots' in Desert acrylic painting, and in Petyarre's work particularly, enact a similar effect.

What is 'inside' is brought 'out'. Penetration effects emergence - the movement is bi-directional-and it is this that creates the quivering, the shimmering, the nervous-liveliness of texture.

What specifically is repeated is the movement from what Warlpiri call kanunju (what is secret, 'underneath' or 'below'where Ancestors now reside having once emerged to walk the landscape and where, in most cases, they have returned to rest) to what is kankarlu (what is in the world as it is seen and known 'above' and in the 'public' domain). In and through the performance of a given Yawulyu, Ancestral presence manifests itself: it is brought kankarlu, above and into the present. ${ }^{20}$

In short, a certain embodied expression of Ancestral presence is effected: in Yawulyu, it is through the productivity of the breast that one 'becomes' ancestor, 'becomes' country. The surface of the body, somatically rendered the same as the surface of the country, allows for this intercorporeal exchange, this inter-changeability by making the two almost identical. This intercorporeality makes for what Warlpiri describe when witnessing a particularly good Yawulyu: they don't say, for example, that Naparrurla is performing or enacting a particularly convincing Ngurlu or Kurlurkuku Jukurrpa (Mulga Seed and/or White Dove Dreaming) - as we might speak of an actor's successful 'portrayal' or 'depiction' - but indeed, Yapa say that she really is 'that one now, that kurlurkuku, that White Dove'. And for the same reasons, Yapa don't say of a 
painting - 'gee, that really "captures” the Dreaming well', or 'fantastic "execution”, 'great representation of Ngurlu, Ngapa, Yankirri' - they say 'Jukurrpa nyarnini, pijirrdi nyarnin jukurrpa'-Dreaming really, strong, true, Dreaming.

The rendering of the breast commensurate with country is not a one-way process. The aim of both Yawulyu and acrylic painting is the care of country-as part of a larger series of what have been described as generalised 'increase' ceremonies in which the livening-up of country - rejuvenating, re-vitalising, 'feeding' certain places, species and persons accordingly-occurs. ${ }^{21}$ This rejuvenating potential of ceremony is perhaps particularly crucial in a context where country is no longer literally inhabited; where acrylic painting, Yawulyu and/or other ritual performances, constitute the only kind of 'care'. Re-creation of country in the contemporary context includes an essential pedagogic function: the teaching about country which is no longer inhabited to children who have no other access to country outside these manifest presentations of it. ${ }^{22}$

We might think of this in terms of yapa living an already intercorporeal, an already syncretic, open relationship to and with Ancestral bodies in their varying manifestations.

If there is no body as such, but only ways of being bodily in culturally and situationally specific terms, then 'becoming' country becomes thinkable in a very literal sense. ${ }^{23}$ If yapa 'become in relation to country' (and I think here of both senses of 'becoming', as 'coming into being' and as 'suit, befit') it is because their own bodies are not produced as bounded, bordered, discrete. If one can speak, in Merleau-Ponty's terms, of a cultural 'corporeal schema'24 - what Rosalyn Diprose defines as a 'set of habits, gestures and conducts formed over time in relation to other bodies' ${ }^{25}$ - one would have to argue that for yapa, this schema is formed, necessarily, in relation to Ancestral bodies and for women, honed and attenuated through the breast. What makes up, what makes for, the potentiality of such a corporeality imbibes, embraces, opens out to, and equally introjects Ancestral habits, sentiments, sensibilities. 
Axiom three: the breast mark is a relation; the mark is a relation to. In the case of these contemporary works, the tremulousness, the animation of the text - the very frisson between mark and surface, depth and background, presence and absence-becomes itself the central motif. The 'inter'-what links the human to the Ancestral, what links the mouth of the feeding child to the breast - and the material conjoining of subjects; in other words, attachment.

By a notion of attachment as mark, I mean to suggest two things. First, that these marks, in a technical semiological sense, are indexical as opposed to the more traditional interpretation of them as iconic. Second, I mean a mark dependent upon a relationship in which differentiation is always troubled; in which absolute differentiation is not secured or guaranteed. The difference between 'surface' and 'mark'; absence and presence; human body and ancestral are not fixed or final. As we know from Derrida, such differences remain indebted to and dependent upon their so-called 'other'; the debt to and detour via something else which he claims is necessary for all signification. ${ }^{26}$ The very frisson of tension, texture, textuality is the binding relation necessary for the differentiation we call the mark (writing).

In the case of the Warlpiri breast, the ambiguity of the debt - the ongoing relation to another for any claim to identity, meaning - is paramount. The literal incapacity to feed oneself, or to breastfeed alone, is here enacted by the very conditions of inscription. Yawulyu inscription is always done by another. It would in fact be physically impossible to self-inscribe, at least in terms of ensuring aesthetic integrity. Moreover, the determinative relation for breast-painting up is kurdungurlu to kirda, that is, matrilineally related so-called kurdungurlu or 'managers' of the particular Dreaming paint so-called kirda or 'owners' of the design. Thus, the very manifestation of Ancestral-becoming is shared across, made relational literally, between kirda and kurdungurlu, 'managers' and 'owners' of the design. This relation ensues in the dance performance, where the manager 'oversees' and 'bosses' the owners; not a happy compatibility but a tension-filled (at least enacted) struggle, which can escalate. Not unlike the infant's ongoing relation to the mother, it is the battle for differentiation in the 
face of dependency that is critical.

What I want to evoke here is not so much the primary object relation of psychoanalysis but a particular phenomenological reading of attachment in which attachment retains its productivity. The carnal taking-in of the breast to feed and to be fed begins a lifelong and ambiguous intercorporeal relation to others. The literal imbibition of nipple, skin - the physical 'latch on', mouth to breast, the 'blind recognition' of empathetic bonding, shared intentions, synchronous movement, mirror imaging; the pleasures, intentions, and sentiments of the mother's body - will mark and make the subject socially and culturally subject to. She will remain throughout her life indebted to, defined by and in relation to the bodies of others - and specifically here, the materiality of country as breast, country as body.

What, after all, does breastfeeding teach the infant, according to Winnicott, but about the very aliveness of the mother? ${ }^{27}$ For the first object is not an object at all but another body; as Merleau-Ponty puts it, 'the very first of all cultural objects, and the one by which all the rest exist, is the body of the other person as the vehicle of a form of behavior'. ${ }^{2} 8$

\section{Axiom four: it is country who is fed; it is country which feeds (the ethnographic reading).}

There are no infants figured in paintings from the Central and Western Desert. Full stop. The omnipotent and omnipresent 'infant' here is country itself. Country is writ even larger because it is never in and of itself represented as or rather, it is always represented as it is materially made and manifest, providing the background 'surface'-skin, country, canvas readied, hungry, primed for the mark.

Kathleen Petyarre's Untitled (1990) is a doubled, ambiguous figure: both feeder and fed; ancestor and human; mother and monster. Here, arguably, the impossible imperative of the breastfeeding relation is evident. This is no maternal gift or sacrificing mother, the stakes here are clear. This is a difficult and dangerous relationship, all consuming, auto-cannibalistic, self-destructive even. A troubled and treacherous attachment: engorgement, the milk fever, mastitis; the voracious infant that feeds feeds feeds and will not settle; the terror and 
likelihood of an all-consuming relation; the law of lactation and its impossible demand. The excessive, unrelenting task of what the mother has been asked to carry has become the explicit theme (and arguably, what all these paintings are about).

This is not Melanie Klein's (cum-Bettleheim's) 'good enough' mother. This instead is the 'terrifying mother'. Klein describes her. It is actually an introjection of the child's perceived threat of the mother's all-consuming desire. ${ }^{29}$ Significantly, Klein argues, the child's dread of the so-called terrifying mother is intensified when the child cannot see the mother. In her account, the presence of the real, loving mother diminishes the introjected dread of the terrifying mother. ${ }^{30}$

To translate: Country is starving without care. Country is figured as infant. Country can only remain fertile, productive if in fact it is looked after, tended to, cared for, fed, properly. And that means work. Ritual, ceremony, what Warlpiri call in English 'business', is a labour of lifelong attachment. Ancestors are dependent upon humans for the making and keeping of their viscera - species, flora, fauna, social relations and relatedness - animated, enlivened, activated, in a word, attached - to lived sentiments and sensibilities.

Not only is country replete with marks and meaning and potencies but these forces are highly ambivalent and potentially dangerous if not tended to in the right way by the right people. The very potencies which stop people from travelling outside their own inhabited country, that make people fearful about entering other people's country; that make people increasingly anxious and frightened of their so-called 'own' country if it has not been inhabited for a long time, are particularly likely in the contemporary era, due to displacement, resettlement, community life.

Not occupying country- not 'seeing' it in Klein's senseincreases anxiety. Not seeing country-not being able to 'look after' country - in the contemporary context is particularly likely, particularly dangerous, particularly anxiety-invoking. The so-called contemporary Aboriginal condition is defined by the violent separation of person from country. The affective dimensions linger, fester and threaten. In this sense, contemporary artworks by women can be seen as both compensatory 
and reparative; a certain attempt to ward off as it seeks to soothe, mother's hands-like, what is an irreparable wound.

Axiom five: to view these works is to participate in their workings. Arguably, all of these contemporary works by women bespeak a specifically female take on the Dreaming, a culturally distinctive intimacy of breasted relation and relatedness. The somatic syncreticism of mother and infant is here evidenced: indebted and dependent, with marks so fine as to be undifferentiated from background; what is foreground, what is background, vacillates and shifts again. Radiant vibrancy, pure animation: it is movement itself which emerges as signified. An animated tremulousness, the quivering enliving design on breast as it dances, the fierce suck of the infant, the pull and rush of the let down, milk as it seeps and weeps, aqueous movement that surges and flows without definite borders but not without pattern, a carving, incising patina. Simultaneously visible and yet rendered invisible, the dots have the effect of making invisible the operation that made them possible: the incapacity to differentiate self and other; a two-way interaction between the tangible and the visible whereby reversibility is enabled. The saturation of the canvas, the saturation of feeling during the feed, the global and multiple pleasures which proliferate, are seemingly only artificially stopped - contained - by the edge of the canvas. This is fecundity in its most literal sense, engorged and dripping, life source, as country is to human and as human marking - making - is to country.

The effect is more ontological than ocular. The movement insists that we enter the surface of the canvas; to move, like the mark, the Ancestor itself, kanunju and kankurulu, down into and to emerge out of again. This is not a geography or a cartography of the breast. My analysis here is explicitly against the dominant idea of these works as 'maps' of country. The vital ingredient necessary in classic Western cartography - perspective, that is, fixed objects against an equally fixed background plane-is here eschewed. There is no where, no way, to position ourselves, as spectators, outside this experience and expression. Can the infant 'see' the breast? Or the mother the infant as it feeds? 
If there is perspective at all here it is vertical rather than horizontal-a three-dimension texture that ripples and undulates. The surface tissue of the canvas re-signs and re-assigns and disappears altogether. There is no focal point for these paintings, or if there is (as in some of Petyarre's) it is vortex-like in its draw, pull and force. That the entire canvas is covered in this totalising experience and expression means that there is no interference, no halting of one's encapturing within the rhythmic mesmerising repetition of line and movement.

The effect is to merge subject with matter-a merging not only of Ancestral body with country, not only Ancestor 'skin' with 'surface' of canvas, but with the body, the skin, of the viewing subject. These works captivate literally. Our bounded bodies, like that of the Ancestors, dissipate. In viewing these paintings, it is impossible not to become immersed in the fleshly enfoldings of their animation. A certain dissolution of the self occurs. A movement, a becoming, which cannot be grasped as knowledge or cognitive fact but can profoundly be witnessed ${ }^{31}$-indeed, must be witnessed in these and only these terms, for there is an exigency in this work that cannot be ignored.

A chiasmic meeting, in Merleau-Ponty's sense occurs; a mutually constitutive relationship between human and so-called non-human, between Warlpiri/Anmatyerr/Alyawarr and Ancestor, between canvas and mark, viewer and viewed..$^{22}$ A chiasmic reversibility in a fleshly sociability where canvas (skin, country) becomes the medium for intercultural and intercorporeal exchange, what Laura Marks might called 'haptic visuality' whereby 'the eyes themselves function like organs of touch.' ${ }^{33}$ There is a metamorphosis in the impact of this embrace of the aesthetic. An evocation of the proximity of mother and child; to see is to touch and be touched. This reversibility both describes and enacts an ongoing interaction between the flesh of the body, the flesh of others and the flesh of this cultural world.

As I have described elsewhere there is no small gift on offer here. ${ }^{34}$ What is explicitly on offer is our participation in this ongoing responsibility to make, to remake, country; an invitation to partake in a denial of the differentiation of body 
from canvas, country from Ancestral body, viewing subject from painting subject, Kardiya from Yapa, Whitefella from Black. There is an imperative to make the body of the viewing subject enlivened through the very act of viewing these works in precisely the same terms in which Ancestors first enlivened country with their own viscera, and in turn, which Warlpiri use to enliven their own bodies, country, canvas; an animation of the body that is country and the animation of a body which is made country. The demand here is to witness a life world in these and only these terms; an imperative that 'we' as viewers equally experience a world made in and through the act of our viewing. To be charged literally with fecundity; to be held, child to breast, relationally - the crucial incarnate participant in a fleshly animation of an embodied embrace.

There is perhaps also a certain holding at abeyance evident here, a 'don't get too close' movement, more noticeable perhaps in the work of Dorothy Napangardi - to be held by, to be clasped firmly; not however to crush. An increasing disassociation, an acknowledgement perhaps even, black and white literally as Napangaridi's is, of the ultimate futility, of the very possibility - the radical political embrace - these works engender.

This is an enactment - at once expression and experience - that is anything but language dependent. This is instead a profoundly wordless occasion. This is an occasion that does not require translation, transcription, white linguists' white pages. In refusing to position Warlpiri, Anmatyerr/ Alyawarr as subservient to English - the cathecretic likelihood of misunderstanding, misspellings, misunderstandings is disallowed. In the contemporary move to use minimal titling, and English-only titling, there is, in fact, no need to speak, to explain, at all. In not opting for the vernacular, there is a profound protection of it in pushing the potential it always already affords - the potential of a distinctive cultural writing that requires no translation at all.

The very kernel of the intercultural encounter is foundnot as understanding another way of life but as inducing a reorienting of a bodily imperative that feels difference as a 'felt reality of relation' in Brian Massumi's terms..$^{35}$ In entering the painting - in being imprinted by it - we experience its relation 
effects; the condition of its emergence, its animational fecundity, corresponds to our animation by it.

To view these paintings is to enter the ambiguity of a specific relation to - a marking and making which requires our participation. It is the spectators' witness which is required to complete, to animate, this incarnate productivity. The breast's fecundity relies on the demand of the child to feed; just as country relies on the labour and witness of the living to ensure it remains not only benevolently oriented to the human but productive in relation to it.

It is however a particular witness we are being asked of here. Fred Myers has defined the Dreaming in the Central Desert context as 'a sensory form to be experienced'. In his account, the Dreaming 'is a manifestation of it but not an account of what it is. ${ }^{36}$ In this sense, contemporary art positions Whitefellas to witness precisely a 'sensory manifestation that is not an account'. No longer are sacred sites, named Ancestors, animal tracks and prints depicted in contemporary painting. No longer do accompanying Dreaming stories 'tell' us narratives or provide information on country, skin group or artist. What is being asked here is not a case of recognition, nor is it a claim for land rights - what von Sturmer claims Aborigines have been demanding for over two hundred years and precisely what has, and is being, denied by the state. ${ }^{37}$ What we are being asked to witness is a cultural way of being, a writing proper, that cannot be spoken back to, that cannot be better written by others. Sacred text as it is written, not what is writ, this is a bodily imperative that relies on our response as a no uncertain demand for responsibility.

\section{Notes}

1 This essay draws on fieldwork with Lajamanu Warlpiri supported by the Australian Institute of Aboriginal and Torres Strait Islander (AIATSIS); the Department of Anthropology, Sydney University and the Department of Anthropology, Macquarie University. I am grateful to Kathleen Petyarre and Penny Hoile of Gallery Australis for permission to reproduce the works included here and to Christopher Hodges, Utopia Art Gallery, for his help in locating Kathleen Petyarre's untitled woodcut.

2 Gilles Deleuze, Francis Bacon: The Logic of Sensation, trans. Daniel W Smith, Continuum, London and New York, 2003 (1981). 
Jennifer L. Biddle, 'Country, Skin, Canvas: The Intercorporeal Art of Kathleen Petyarre', Australian and New Zealand Journal of Art, vol. 4, no. 1, 2003, pp. 61-76; 'Writing Without Ink', in Alison Lee and Cate Poynton (eds), Culture and Text, Allen \& Unwin, Sydney, 2000, pp. 170-87; 'Inscribing Identity: Skin as Country in the Central Desert', in Sara Ahmed and Jackie Stacey (eds), Thinking Through the Skin, Routledge, London and New York, 2001, pp. 177-93.

John von Sturmer, 'R Stands For ... An Extract from a Mabo Diary', Australian Journal of Anthropology, vol. 6, no. 1-2, 1995, pp. 101-16.

5 Judith Butler, Excitable Speech: A Politics of the Performative, Routledge, New York, 1997, and Judith Butler, Bodies That Matter: On the Discursive Limits of 'Sex', Routledge, New York, 1993.

6 It isn't arbitrary that younger women are recalcitrant to perform Yawulyu in public or, if they do so, prefer wearing a bra to dance, putting the bra back on after they are painted up in an act which both conceals the so-called 'naked' breast and simultaneously constrains its movement. Shame, I have explored in my work, is a dominant Warlpiri experience and expression, one particularly likely to be incited by colonial contexts, attitudes, sentiments. The preference for many younger women, and even some older women, to adorn a bra in Yawulyu is, arguably, indicative of both the degree to which the bra has become part of the 'habitus' of contemporary bodies and, in turn, the degree of kurnta or shame potentially engendered by not wearing one publicly. See Jennifer L. Biddle, 'Shame', Australian Feminist Studies, vol. 12, no. 26, 1997, pp. 227-40.

7 For Lajamanu Warlpiri see Judith Ryan, Paint Up Big: Warlpiri Women's Art of Lajamanu, National Gallery of Victoria, Melbourne, 1990, and for Utopia see Utopia Body Paint: Australian Aboriginal Art, Exhibition Catalogue, Austral Gallery, St Louis, ND.

8 Nancy Munn, 'The Transformation of Subjects into Objects in Walbiri and Pitjantjatjara Myth', in Ronald M Berndt (ed.) Australian Aboriginal Anthropology, University of Western Australian Press, Perth, 1971.

9 Annette Hamilton, 'Kinship and Gender', in Sylvia Kleinert and Margo O’Neil (eds), Oxford Companion to Aboriginal Art and Culture, Oxford University Press, Melbourne, 2000, pp. 60-75.

10 Mervin J. Meggitt, Desert People: A Study of the Walbiri Aborigines of Central Australia, Angus \& Robertson, Sydney, 1962, pp. 270-80.

11 Christine Watson, 'Touching the Land: Towards an Aesthetic of Balgo Contemporary Painting', in H. Morphy and M. Smith-Bowles (eds), From the Land: Dialogues with the Kluge-Ruhe Collection of Aboriginal Art, University of Virginia, Charlottesville, 1999.

12 Jacques Derrida, 'Signature, Event, Context', in Derrida, Limited Inc, trans. Samuel Weber and Jeffrey Mehlman, Northwestern University Press, Evanston, 1990.

13 Warlpiri Lexicography Group, Warlpiri-English Dictionaries, Centre for Cognitive Science, Massachusetts Institute of Technology, Cambridge, 1986, 'Verbs', p. 24.

14 Jacques Derrida, Of Grammatology, trans. Gayatri Chakravorty Spivak, Johns Hopkins University Press, Baltimore, 1976, and Derrida, 'Signature, Event, Context', particularly. Elizabeth Hill Boone and Walter D. Mignolo (eds), 'Writing Without Words: Alternative Literacies', in Mesoamerica and the Andes, Duke University Press, Durham, 1994.

15 Roland Barthes, The Pleasure of the Text, trans. R Miller, Hill and Wang, New York, 1975, p. 10.

16 Barbara Glowczewski, Yapa: Peintres Aborigènes de Balgo et Lajamanu, Baudoin Lebon, Paris, 1991, p. 121. 
17 Francois Dussart, 'A Body Painting in Translation', in Marcus Banks and Howard Morphy (eds), Rethinking Visual Anthropology, Yale University Press, New Haven and London, 1997.

18 Michael Jackson, Minima Ethnographica: Intersubjectivity and the Anthropological Project, University of Chicago Press, Chicago, 1998, p. 132.

19 Watson.

20 As argued by Glowczewski, p. 121.

21 Nicolas Peterson, Change and the Aboriginal: A Traditional Life, A Conservative History, Australian Government Publishing Service, Canberra, 1970.

22 See for example Warlukurlangu Artists, Kuruwar: Yuendumu Doors, Australian Institute of Aboriginal Studies, Canberra, 1987.

23 As is argued by scholars such as Gail Weiss, Body Images: Embodiment as Intercorporeality, Routledge, New York, 1999; Rosalyn Diprose, The Bodies of Women: Ethics, Embodiment, and Sexual Difference, Routledge, New York, 1994, and Rosalyn Diprose, Corporeal Generosity: On Giving with Nietzsche, MerleauPonty, and Levinas, State University of New York Press, Albany, 2002; Elizabeth Grosz, Volatile Bodies: Toward a Corporeal Feminism, Allen \& Unwin, Sydney, 1994.

24 Maurice Merleau-Ponty, 'The Child's Relations with Others', in J Edie (ed.), The Primacy of Perception and Other Essays on Phenomenological Psychology, and Philosophy of Art, History and Politics, Northwestern University Press, Evanston, 1964.

25 Diprose, The Bodies of Women, p. 105.

26 Jacques Derrida, 'Difference', in Margins of Philosophy, trans. A. Bass, University of Chicago Press, Chicago, 1982.

27 Donald W. Winnicott, Psychoanalytic Explorations, Harvard University Press, Cambridge, 1989.

28 Maurice Merleau-Ponty, Phenomenology of Perception, trans. Colin Smith, Routledge and the Humanities Press, London and New Jersey, 1989, p. 348.

29 Melanie Klein, The Selected Melanie Klein, Juliet Mitchell, Penguin Books, Harmondsworth, 1986.ed.

30 Klein, p. 92.

31 By witness, I mean the culturally specific and ontological sense that Basil Sansom evokes in the Aboriginal context, that is, the determinative reliance on the other's presence and acknowledgment - the other's 'witness' - to constitute an event as happening, as meaningful, as mattering. See Basil Sansom, The Camp at Wallaby Cross: Aboriginal Fringe-Dwellers in Darwin, Australian Institute of Aboriginal Studies, Canberra, 1980.

32 Maurice Merleau-Ponty, 'The Intertwining: The Chiasm', in The Visible and the Invisible, trans. Alphonso Lingis, Northwestern University Press, Evanston, 1968, pp. 130-55.

33 Laura U. Marks, The Skin of the Film: Intercultural Cinema, Embodiment, and the Senses, Duke University Press, Durham, 2000, p. 2. Marks is here characterising 'intercultural' cinema as marked by 'haptic visuality' but her analysis of the way in which this cinema of the displaced and diasporic operates in terms of inciting corporeal memories and history because of a necessarily traumatic (postcolonial) relationship to memory and history, can well be extended to the work of Petyarre.

34 Biddle, 'Country, Skin, Canvas'.

35 Brian Massumi, Parables for the Virtual: Movement, Affect, Sensation, Duke University Press, Durham, 2002.

36 Fred Myers, 'Ontologies of the Image and Economies of Exchange', American Ethnologist, vol. 31, no. 7, 2004, pp. 1-16. von Sturmer. 


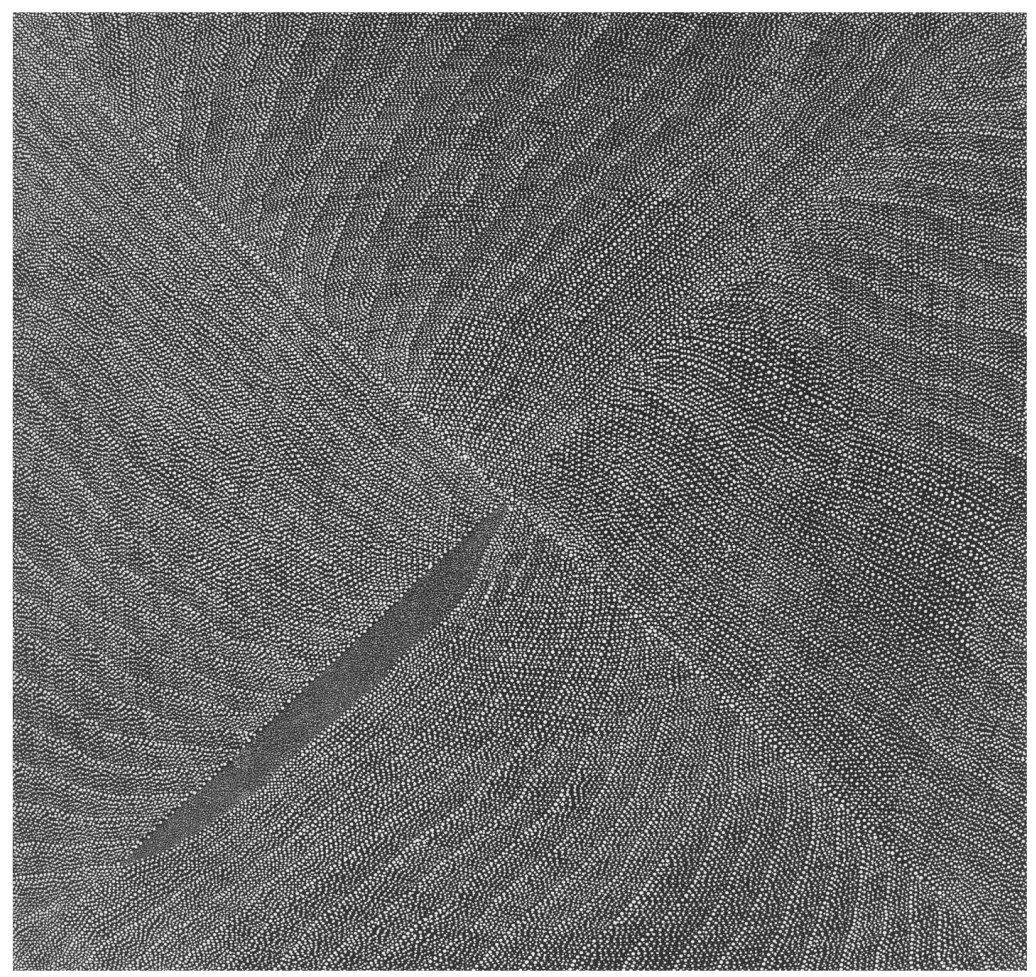

$1 \quad$ Kathleen Petyarre

Mountain Devil Lizard Dreaming (After Sandstorm), 1998

Synthetic polymer on Belgian linen $122 \times 122 \mathrm{~cm}$

Private collection

Courtesy of Kathleen Petyarre and Penny Hoile, Gallerie Australis, Adelaide 

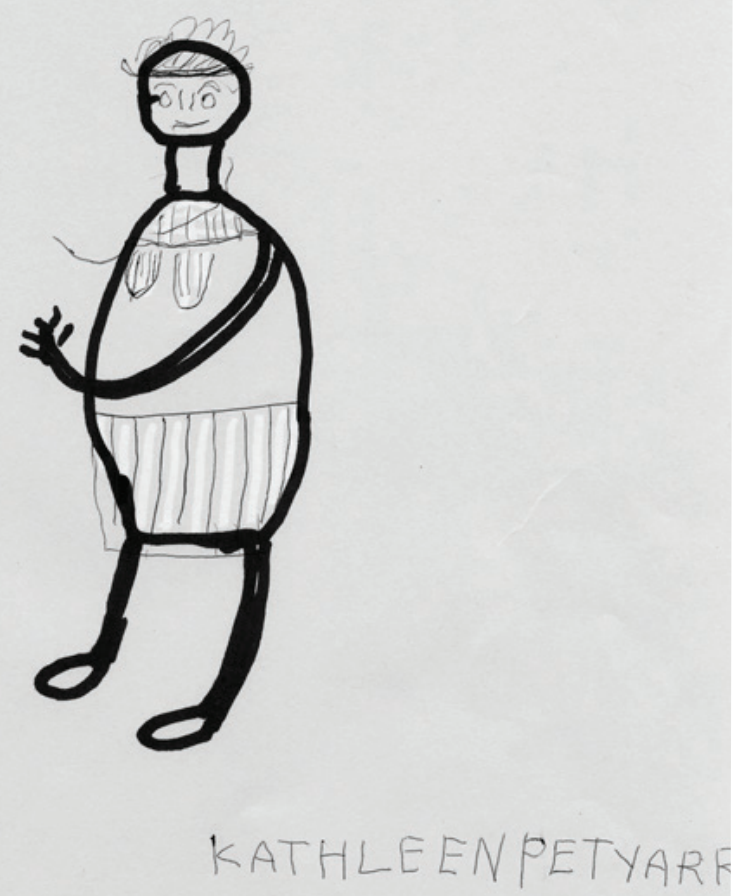

Untitled, 2004

Line drawing

Photograph courtesy of Christine Nicholls

Image courtesy of Kathleen Petyarre and Penny Hoile, Gallerie Australis, Adelaide 


\section{KATHLEEN PETYARRE}

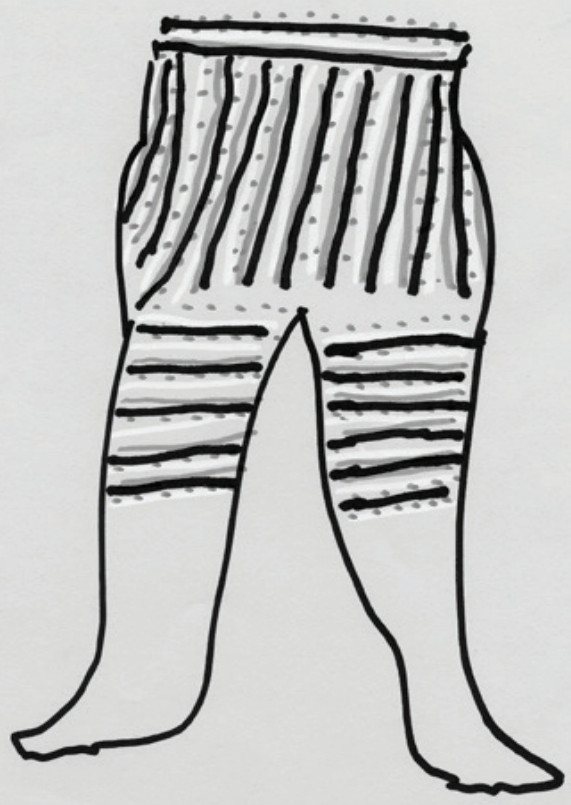

Kathleen Petyarre

Untitled, 2004

Line drawing

Photograph courtesy of Christine Nicholls

Image courtesy of Kathleen Petyarre and Penny Hoile, Gallerie Australis, Adelaide 


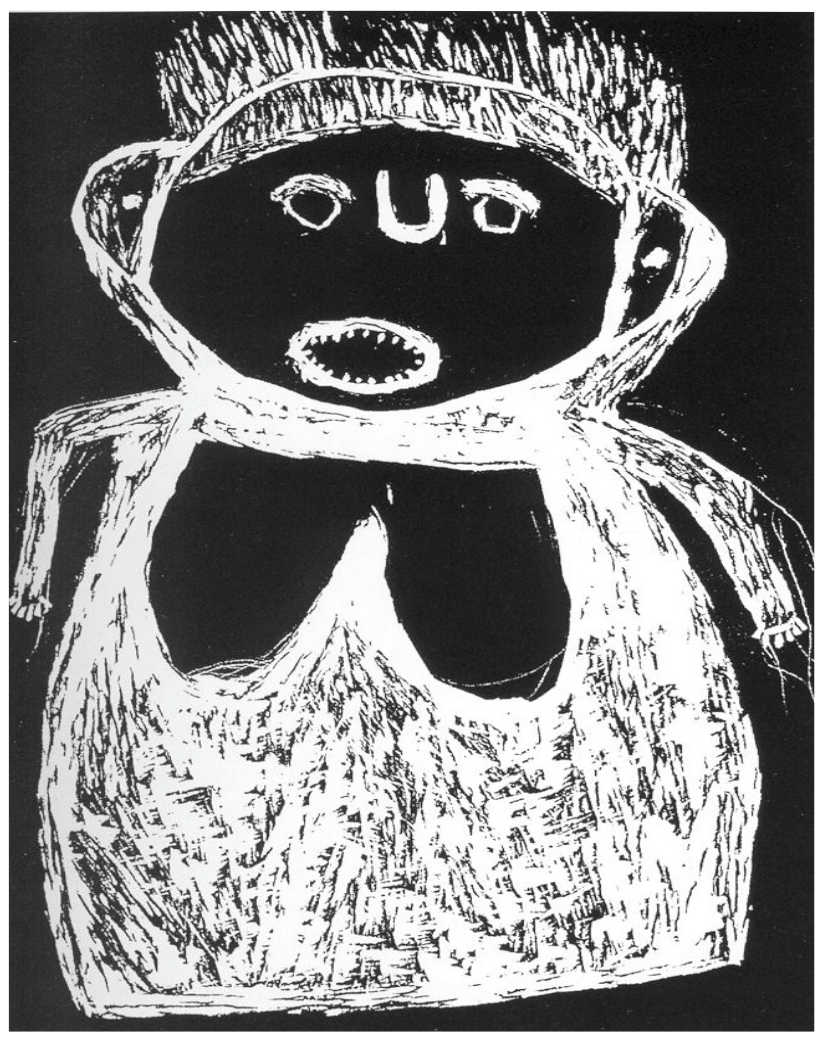

4 Kathleen Petyarre

Untitled, 1990 (from Utopia print series)

Wood cut $45 \times 30 \mathrm{~cm}$

Photography courtesy Christopher Hodges, Utopia Arts, Sydney Image courtesy Art Gallery of New South Wales

Courtesy of Kathleen Petyarre and Penny Hoile, Gallerie Australis, Adelaide 